\title{
ANALISIS SUMBER-SUMBER AIR PADA DAERAH ALIRAN SUNGAI (DAS) KARAJAE DALAM MENUNJANG KETERSEDIAN AIR BAKU KOTA PARE-PARE
}

\section{(Analysis of Water Sources in Karajae Watershed Flows in Supporting Raw Water Availability Pare-Pare City)}

\author{
Mulyadi \\ Mahasiswa Program Studi Magister Agroekoteknologi \\ Universitas Muslim Indonesia \\ Email:eko_sp80@yahoo.co.id
}

\begin{abstract}
This study aims to (1) Determine land cover in the Karajae watershed area. (2) Identifying the Location of Water Sources through Soil Analysis of Water Assessment Tools (SWAT). (3) Make a map describing the unit of land available and the location of the water source in the Karajae watershed. This research was conduct in the Karajae Watershed from July to September 2017. Primary data is obtained directly through the interpretation of satellite imagery to make land cover maps. Retrieval of data on land cover in the field doing by adjusting the classification of land cover in the field with the results of the interpretation of satellite imagery purposively base on accessibility. Secondary data is data covering the general condition of the research location obtained from the study of literature and other data related to research. The secondary data includes the DAS Boundary Map, River Network Map, DEM 30m Aster, 2016 Land Closure Map, Soil Type Map, Climate Data. This study used the SWAT model. The results obtained from this study are the 2016 Landsat Image Interpretation Results 2016 and the Karajae watershed field check results. There are 11 types of land cover which are dominated by dryland agriculture with a percentage of land area of $35.1 \%$ followed by shrubland cover with an area of $17.0 \%$ and bush mixed dryland agriculture with a percentage of the area of $12.5 \%$ and low-density dryland forest with a percentage of the area by $12.2 \%$. Land cover has the smallest percentage of area, namely ponds by $0.2 \%$. The results of SWAT analysis identification obtained 17 sub-watersheds as water sources that have high water availability, spread in three districts, namely Sidenreng Rappang, Barru District and Pare-Pare City. The results of the classification of water availability values in 17 sub-watersheds that have high water availability values, namely the western Bacukiki sub-watershed, located in the City of Pare-pare where the sub-watershed covers 4 villages namely new Bojo, Bumi Harapan, Lumpue, Wattang Bacukiki with the availability value water of 133,952,197.80 $\mathrm{m}^{3}$.
\end{abstract}

Keywords: Land closure; Water availability; SWAT

\section{PENDAHULUAN}

Daerah aliran sungai

(DAS) merupakan wadah yang menyimpan berbagai macam sumberdaya alam, terutama vegetasi, tanah dan air serta tempat hidup manusia dalam mengelola sumberdaya alam tersebut untuk memenuhi kebutuhan hidupnya (Paimin,
2012). Pengelolaan DAS merupakan pengelolaan sumberdaya alam dengan tujuan untuk memperbaiki, memelihara dan melindungi keadaan DAS, agar dapat menghasilkan barang dan jasa khususnya kuantitas, kualitas dan kontinuitas air untuk kepentingan pertanian, kehutanan, 
perkebunan, peternakan, perikanan, pada SK.511/MENHUT-V/2011 tentang industri dan masyarakat.

Berdasarkan data Land Cover dari penetapan peta DAS. Pembuatan batas hasil analisis citra landsat tahun 2010 luas Hutan di daerah DAS Karajae 13.206,53 ha.

Daerah Aliran Sungai (DAS) Karajae dengan luas 18.000 ha dan memiliki dua wilayah kabupaten/Kota, yakni Kabupaten Sidrap dan Kota Parepare.Daerah Aliran Sungai Karajae merupakan Kawasan Pertumbuhan Ekonomi Terpadu (Kapet) Pare-pare yang menjadi pusat industri, perdagangan, pertanian, peternakan, energi dan transportasi laut.Sungai Karajae juga sebagai penyedia sumber air bagi masyarakat yang dikelola oleh PDAM Kota Pare-pare yang kini telah mengalami defisit air.Banyaknya aktifitas yang terjadi di pinggiran sungai Karajae seperti perkebunan, pembangunan perumahan dan pertambangan mengakibatkan debit air sungai Karajae mulai menurun.

\section{METODOLOGI}

\section{Penentuan Batas Lokasi Penelitian}

Penentuan lokasi penelitian diperoleh dari batas Daerah Aliran Sungai (DAS) yang dikeluarkan oleh instansi terkait yang penetapannya didasarkan

\section{Metode pengumpulan danpengolahan data}

Data yang dikumpulkan dalam penelitian ini meliputi data primer dan data sekunder.Data primer diperoleh secara langsung melalui kegiatan interpretasi citra satelit untuk membuat peta penutupan lahan.Pengambilan data penutupan lahan di lapangan dilakukan dengan menyesuaikan klasifikasi penutupan lahan di lapangan dengan hasil interpretasi citra satelit secara purposive berdasarkan aksesibilitas.Data sekunder adalah data yang meliputi keadaan umum lokasi penelitian yang diperoleh dari studi literatur maupun data-data lain terkait penelitian. Data sekunder tersebut meliputi Peta Batas DAS, Peta Jaringan 
Sungai, Aster DEM 30 m, Peta Penutupan Lahan 2017, Peta Jenis Tanah, Data Iklim.

\begin{tabular}{cll}
\hline \hline No. & Judul & Sumber \\
\hline \hline 1 & Peta Batas DAS & SK 511 Menhut 2011 tentang Penetapan Peta DAS \\
2 & Jaringan Sungai & Badan Informasi Geospasial \\
3 & Aster DEM 30 m & Earth Explorer dan analisis Topo to Raster \\
4 & Peta Penutupan Lahan & Citra Landsat 8 Path 116 Row 63 tahun 2016 \\
5 & Peta Jenis Tanah & RePPProt 1987 \\
6 & Data Iklim & Global Weather tahun 2003-2013 \\
\hline \hline
\end{tabular}

Input Data Soil Water berupa jenis dan parameter fisik dan kimia AssesmentTool(SWAT)

\section{Data Penutupan Lahan}

Data penutupan lahan DAS Karajae tahun 2017 diperoleh dengan cara menginterpretasi citra landsat 8 Path $=$ 114 Wrs Row $=63$ tahun 2017. Citra disediakan oleh United States Geological Survey dan dapat diunduh di website http://earthexplorer.usgs.gov.Metode delineasi visual digunakan untuk menetapkan kelas penutupan lahan berdasarkan pola dan karakteristik yaitu rona, warna, dan tekstur pada citra tersebut.Kemudian dilakukan pengecekan lapangan.

\section{Data Jenis Tanah}

Data jenis tanah diperoleh dari data sistem lahan (landsystem) Regional Physical Planning Programme for Transmigration (RePPProt) Badan Kordinasi Survey dan Pemetaan Nasional Tahun 1987. Kebutuhan input data tanah dalam model SWAT yaitu data tanah tanah. Sehingga diperlukan untuk memasukkan parameter SWAT yang akan dilakukan untuk analisis. Analisis pendekatan yang digunakan adalah dengan mengekstraksi informasi tanah dari peta RePPProt yang dikombinasikan dengan informasi dari Web Soil USDA Natural Resource Conservation Service. Adapun input parameter jenis tanah yang diperlukan untuk menjalankan ArcSWAT dapat dilihat pada Tabel 4 (Neitsch, dkk, 2012).

\section{Data Kelerengan}

Data kelerangan merupakan hasil dari menjalankan program ArcSWAT. Dengan klasifikasi kelas lereng yang digunakan yaitu $0-8 \%, 8-15 \%, 15-25 \%, 25-40 \%$, dan $>45 \%$.

\section{Data Iklim}

Data iklim diperoleh dari data global terkait yaitu Global Weather.Data iklim tersebut dapat diperoleh melalui website http://globalweather.tamu.edu/.Data iklim 
yang dibutuhkan berupa data (curah hujan, temperatur, radiasi matahari, kelembaban udara, dan kecepatan angin) yang merupakan perhitungan harian mulai 2003-2013.Adapun nomor stasiun curah hujan yang ada di DAS Karajae yaitu 421194, 391194, 361194, 421197, 391197, 361197, 421200, 391200 dan 361200 .

\section{Pembentukan Hydrological Response Unit}

Hydrological Response Unit atau disingkat HRU merupakan unit terkecil dalam skala analisis yang dilakukan pada pemodelan SWAT. Pembentukan HRU dilakukan dengan overlay peta penutupan lahan, peta jenis tanah, dan data kemiringan lereng. Setiap HRU yang terbentuk berisi informasi spesifik mengenai lahan tersebut yang mencakup penutupan lahan, jenis tanah, dan kemiringan lereng.Data penutupan lahan dan jenis tanah yang digunakan dalam analisis HRU berformat raster ESRI sedangkan klasifikasi kelas lereng berasal dari dataset DEM yang digunakan untuk mendelineasi batas DAS. Dataset yang digunakan menggunakan sistem proyeksi yang sama(Ditjen Bina Pengelolaan DAS dan Perhutanan Sosial, 2014).

\section{Penggabungan Hydrological Response Unit dengan Data Iklim}

Penggabungan HRU dan data iklim dilakukan setelah satu analisis terbentuk. Pada tahap ini dilakukan pemanggilan file WGN (Weather Generator Data) yang telah diatur sebelumnya. Data series curah hujan $(\mathrm{mm})$, temperatur udara $\left({ }^{\circ} \mathrm{C}\right)$, radiasi matahari (MJ/m2/hari), kelembaban udara (\%), dan kecepatan angin $(\mathrm{m} / \mathrm{dtk})$. Data-data tersebut dikumpulkan kedalam file PCP untuk curah hujan, TMP untuk temperatur, SOLAR untuk radiasi matahari, RH untuk kelembaban udara, dan WIND untuk kecepatan angin dengan ekstensi .txt. Proses simulasi dijalankan berdasarkan periode bulanan.

\section{Simulasi Model Soil and WaterAssesment Tool}

Simulasi model SWAT dilakukan setelah penggabungan proses penggabungan HRU dengan data iklim selesai. Proses simulasi dijalankan berdasarkan periode bulanan. Dengan data yang disimulasikan sebanyak 10 tahun. Model SWAT dapat dijalankan di ArcSWAT dengan menu SWAT Simulation dengan syarat tahapan Watershed Delineation, HRU Analysis, 
dan Write Input Tables telah selesai dengan baik.

Setelah tahapan simulasi telah dilakukan dengan menggunakan proses Run SWAT, tahapan selanjutnya ialah menampilkan hasil output dari simulasi. Proses tersebut dilakukan dengan menggunakan sub menu Read SWAT Output. Hasil output dari simulasi kemudian disimpan untuk keperluan analisis berikutnya.

\section{Ketersediaan Air}

Pada tahapan ini output simulasi model SWAT didefinisikan. Dalam model SWAT ketersediaan air diistilahkan dengan water yield (hasil air) yang diperoleh pada masing-masing subdas dengan satuan $\mathrm{mm}$. Water yield diperoleh dari hasil perhitungan menggunakan rumus berikut ini :

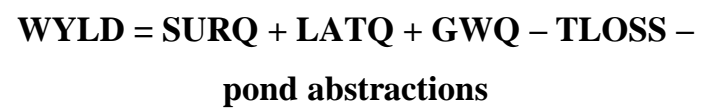

Dimana:

WYLD = Jumlah air efektif yang tersedia dalam suatu DAS (mm)

SURQ = Jumlah aliran permukaan yang mencapai sungai utama (mm)

LATQ = Jumlah air yang mengalir secara lateraldibawah permukaan yang berkontribusi terhadap debit sungai (mm)
GWQ = Jumlah air yang mengalir di aquifer yang berkontribusi terhadap debit sungai $(\mathrm{mm})$

TLOSS $=$ Total kehilangan air ke aquifer $(\mathrm{mm})$

\section{Pemetaan Tingkat Ketersediaan Air}

Setelah output ketersediaaan air didefinisikan tahapan selanjutnya adalah membuat rentang kelas ketersediaan air untuk mengetahui tingkat ketersediaan air di wilayah tersebut. Rentang kelas ketersediaan air diperoleh dari rumus interval kelas yaitu dengan mengurangkan nilai tertinggi dan nilai terendah lalu membagi sesuai dengan kelas yang diinginkan, sehingga diperoleh nilai interval.Kelas interval yang digunakan adalah rendah, sedang, dan tinggi.Setelah diperoleh data kelas interval, selanjutnya memetakan tingkat ketersediaan air dengan menggunakan sistem informasi geografis.

\section{HASIL DAN PEMBAHASAN}

\section{Kelerengan}

Secara umum tingkat kemiringan lereng di wilayah DAS Karajae mengikuti ketinggian tempatnya.Hal tersebut ditunjukkan oleh hasil analisis kontur yang merupakan dasar dalam pembuatan klasifikasi kelas kemiringan lereng. 
Klasifikasi kelas kemiringan lereng pada yakni datar, landai, agak curam, curam DAS Karajae dibagi ke dalam lima kelas dan sangat curam.

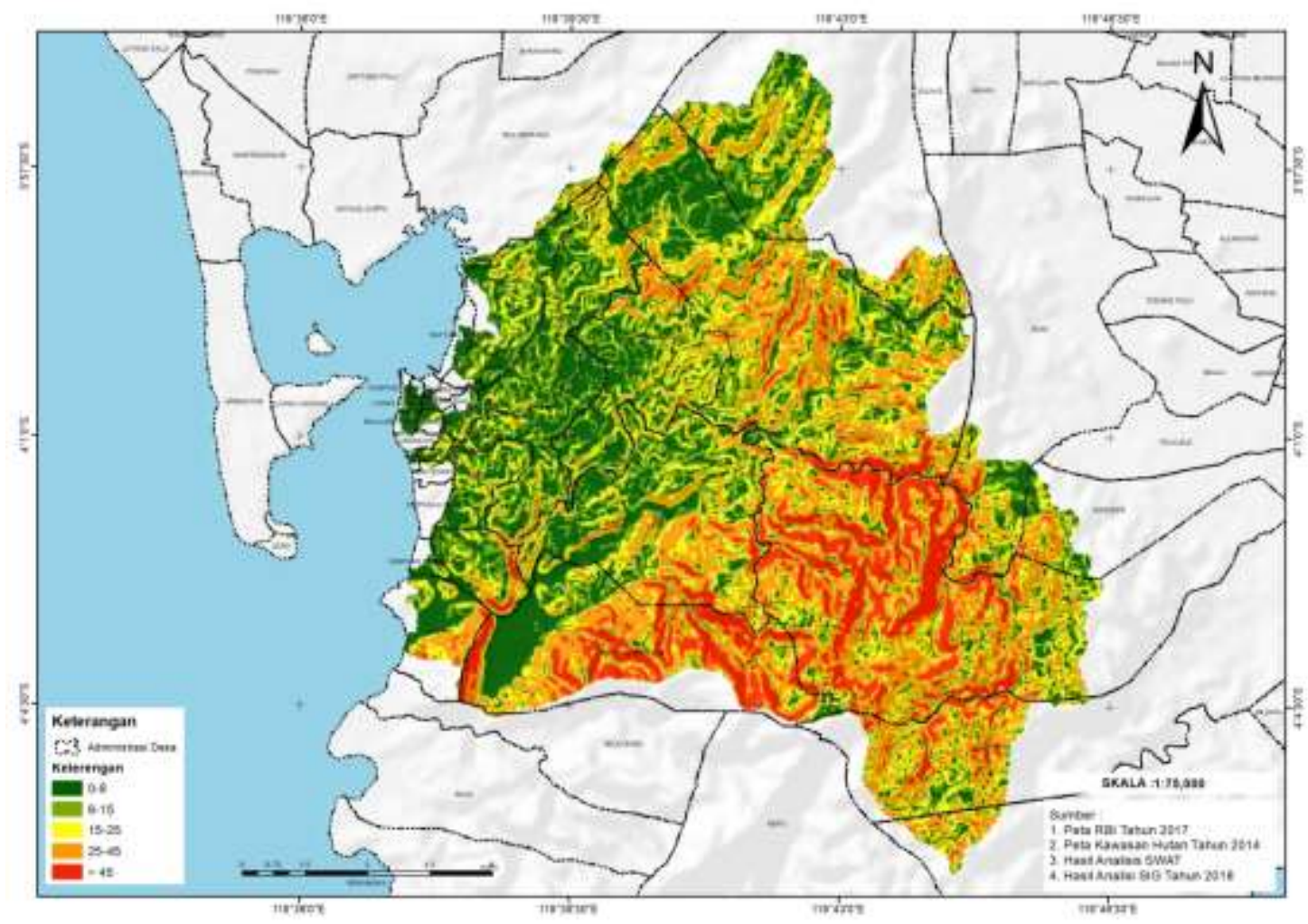

Klasifikasi Kelas Kemiringan Lereng pada DAS Karajae (Hasil Analisis Data GDEM, 2017)

\begin{tabular}{cccc}
\hline \hline No & Keterengan & Luas (ha) & Persentase (\%) \\
\hline \hline 1 & $0-8$ & $4,078.22$ & 23 \\
2 & $15-25$ & $3,941.91$ & 22 \\
3 & $25-45$ & $4,397.31$ & 24 \\
4 & $45-9999$ & $1,996.74$ & 11 \\
5 & $8-15$ & $3,710.74$ & 20 \\
\hline \hline & Total & $\mathbf{1 8 , 1 2 4 . 9 2}$ & $\mathbf{1 0 0}$ \\
\hline
\end{tabular}

Sumber: Analisis SIG

\section{Jenis tanah}

Data spasial yang digunakan untuk analisis tanah diperoleh dari data sistem lahan (landsystem) Regional Physical Planning Programme for Transmigration
(RePPProt) Badan Kordinasi Survey dan

Pemetaan Nasional Tahun 1987.Dari data tersebut dapat diketahui bahwa terdapat 5jenis tanah di DAS Karajae. 


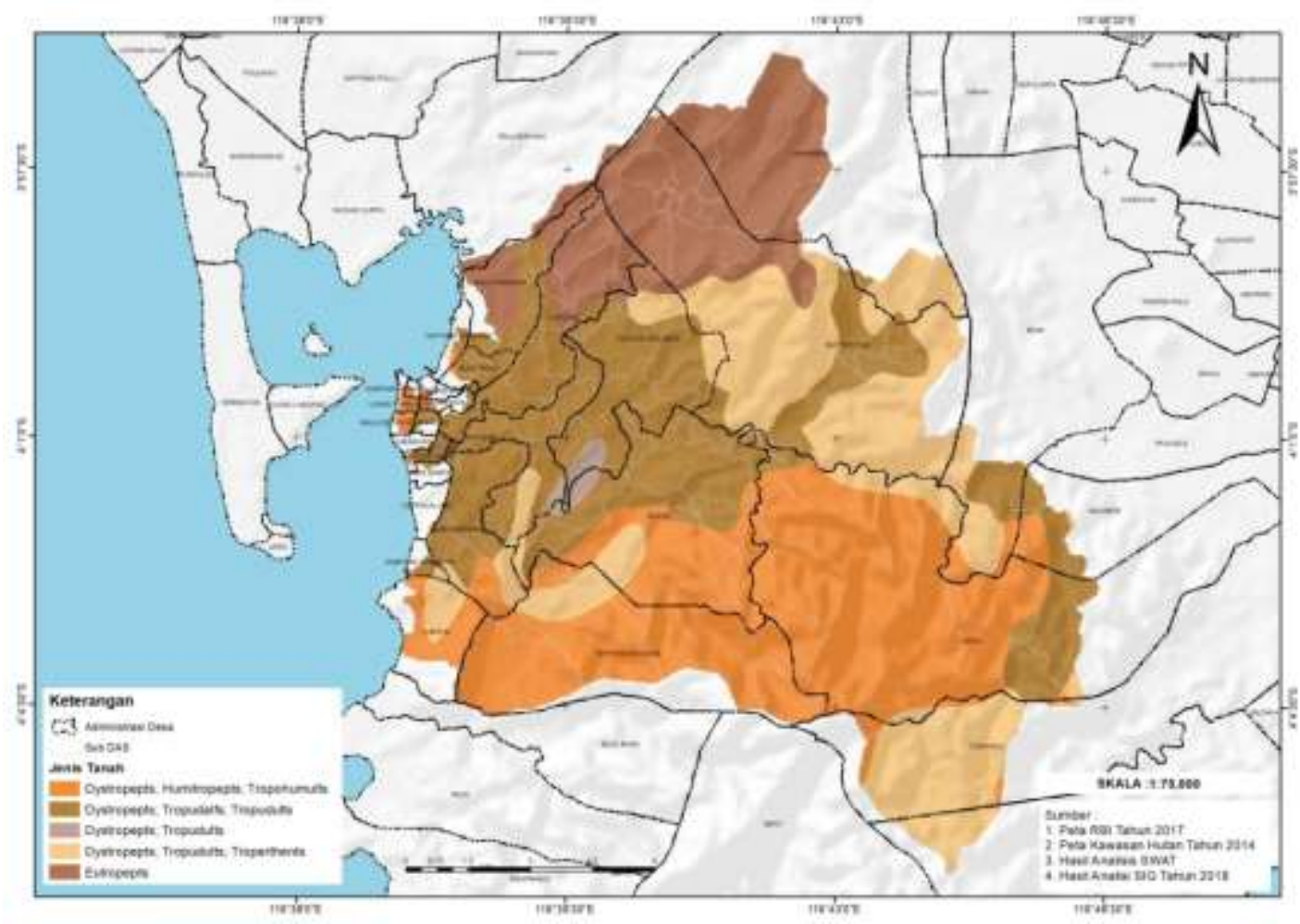

\section{Iklim dan Curah Hujan.}

Data iklim yang digunakan diperoleh dari Global Weather periode 10 tahun, dimulai dari tahun 2003 s/d 2013, pada sembilan stasiun cuaca yang berada disekitar wilayah DAS Karajae. Berdasarkan hasil analisis kondisi iklim pada DAS diketahui bahwa musim penghujan di DAS Karajae dimulai pada bulan November hingga bulan Mei dan musim kemarau dimulai pada bulan Agustus hingga bulan September. Berdasarkan klasifikasi Umumnya tipe iklim di Indonesia ditetapkan menurut klasifikasi Schmit dan Ferguson dengan perbandingan rata-rata jumlah bulan kering.

\section{Penutupan Lahan}

Penutupan lahan diperoleh dari hasil analisis Interpretasi Citra Landsat 8 tahun 2016 dan hasil pengecekan lapangan DAS Karajae.Terdapat 11 jenis penutupan lahan yang didominasi oleh pertanian lahan kering, semak belukar dan pertanian lahan kering campur semak serta hutan lahan kering kerapatan rendah. Agar data penutupan lahan dapat digunakan pada model SWAT, maka penamaan penutupan tersebut harus disesuaikan dengan klasifikasi penamaan model SWAT. 


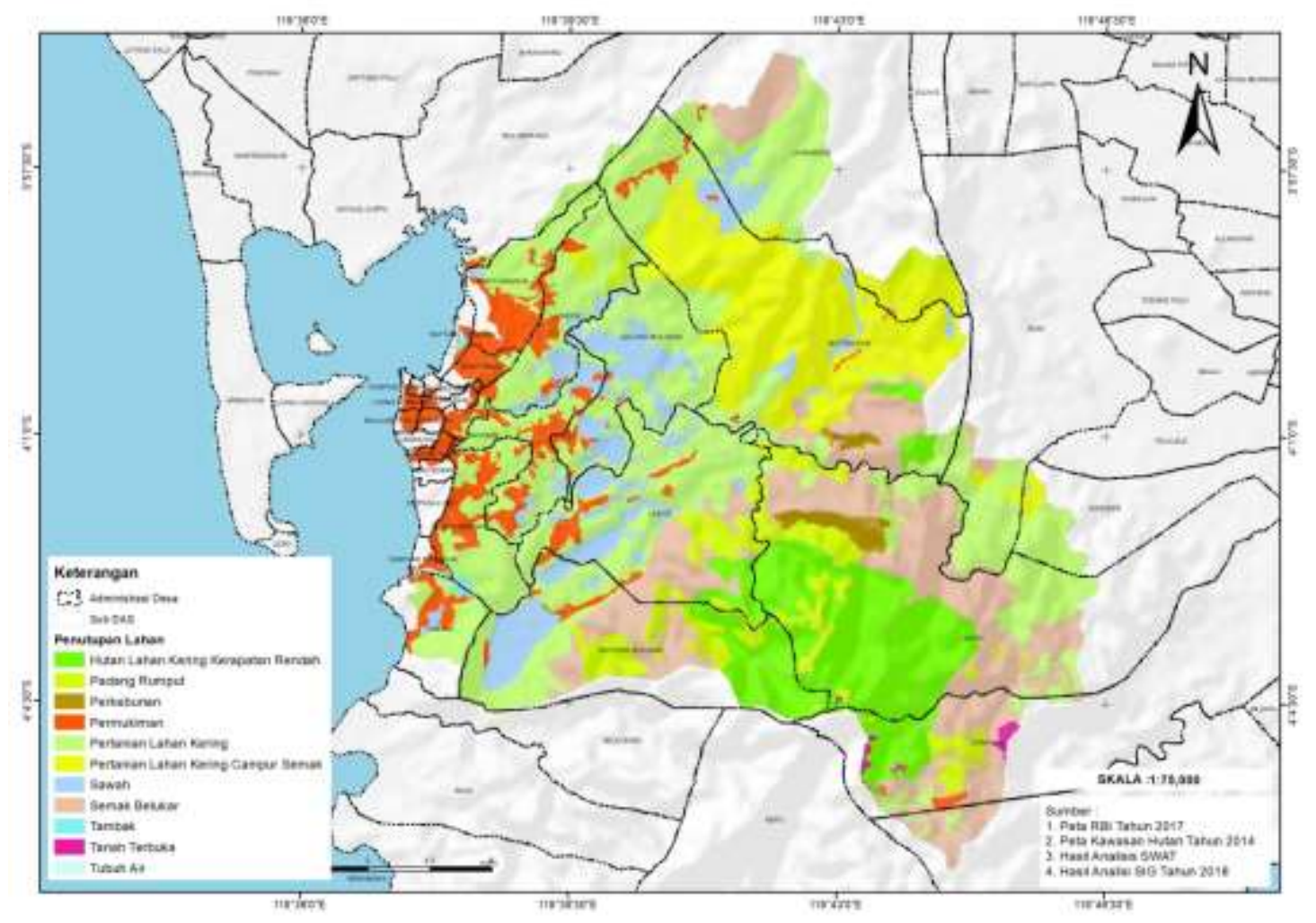

\section{Uji Akurasi Penutupan Lahan}

Hasil interpretasi citra landsat tahun 2016 berupa kelas penutupan lahan dilakukan uji akurasi.Uji akurasi dilakukan untuk mengetahui sejauh mana keakuratan interpretasi citra yang telah diklasifikasikan. 
Mulyadi : Analisis Sumber-sumber Air pada Daerah Aliran Sungai (DAS) Karajae dalam Menunjang Ketersediaan Air Baku Kota Pare-pare

Confusion matriks titik pengecekan masing-masing kelas Penutupan lahan

\begin{tabular}{|c|c|c|c|c|c|c|c|c|c|c|c|c|}
\hline \multirow{2}{*}{$\begin{array}{c}\text { Kelas } \\
\text { Penutupan }\end{array}$} & \multicolumn{11}{|c|}{ Data Pengecekan Lapangan Tahun 2016} & \multirow{2}{*}{$\begin{array}{c}\text { Total } \\
\text { Kolo } \\
\text { m }\end{array}$} \\
\hline & C1.16 & C1.2 & C1.3 & C1.4 & C1.5 & C1.6 & C1.7 & C1.8 & C1.9 & $\mathrm{C} 1.10$ & C1.11 & \\
\hline C1.1 & 8 & 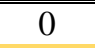 & 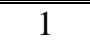 & 0 & 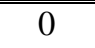 & 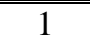 & 0 & 0 & 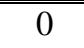 & 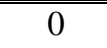 & 0 & 10 \\
\hline $\mathrm{C} 1.2$ & 0 & 8 & 0 & 0 & 1 & 1 & 0 & 0 & 0 & 0 & 0 & 10 \\
\hline $\mathrm{C} 1.3$ & 0 & 0 & 10 & 0 & 0 & 0 & 0 & 0 & 0 & 0 & 0 & 10 \\
\hline $\mathrm{C} 1.4$ & 0 & 0 & 0 & 10 & 0 & 0 & 0 & 0 & 0 & 0 & 0 & 10 \\
\hline $\mathrm{C} 1.5$ & 0 & 0 & 0 & 0 & 10 & 0 & 0 & 0 & 0 & 0 & 0 & 10 \\
\hline C1.6 & 0 & 1 & 0 & 0 & 1 & 8 & 0 & 0 & 0 & 0 & 0 & 10 \\
\hline $\mathrm{C} 1.7$ & 0 & 0 & 0 & 0 & 0 & 0 & 10 & 0 & 0 & 0 & 0 & 10 \\
\hline C1.8 & 0 & 0 & 1 & 0 & 0 & 2 & 0 & 7 & 0 & 0 & 0 & 10 \\
\hline C1.9 & 0 & 0 & 0 & 1 & 0 & 0 & 0 & 0 & 8 & 0 & 1 & 10 \\
\hline $\mathrm{C} 1.10$ & 0 & 3 & 0 & 0 & 0 & 0 & 0 & 0 & 0 & 7 & 0 & 10 \\
\hline $\mathrm{C} 1.11$ & 0 & 0 & 0 & 0 & 0 & 0 & 0 & 0 & 0 & 0 & 10 & 10 \\
\hline Total Baris & 8 & 12 & 12 & 11 & 12 & 12 & 10 & 7 & 8 & 7 & 11 & 96 \\
\hline
\end{tabular}

Jumlah titik koordinat yang tidak mengalami perubahan penutupan penggunaan

Hidrologic Response Unit (HRU)

Berdasarkan hasil parameter input SWAT selanjutnya overlayakandilakukan dengan menggunakan HRU analysis, menghasilkan unit respon hidrologi (HRU). Unit respon hidrologi yang terbentuk sebanyak 1.870unit. Luasan terkecil dari unit yang terbentuk adalah 0,09 ha, sedangkan luasan terbesar sekitar 175,4 ha. Dari hasil analisis HRU proses tahapan selanjutkan memasukkan data iklim. Data iklim ini terbagi atas 5 bagian yang menjadi variabel perhitungan ketersediaan air. Data tersebut diantaranya, curah hujan, kelembapan relatif, kecepatan angin, radiasi matahari dan temperature, lima data tersebut diproses melalui running Write SWAT Database Tabel. Setela proses pengimputan data iklim dengan periode 10 tahun maka diperoleh hasil data running SWAT. Berikut gambar proses running SWAT. 


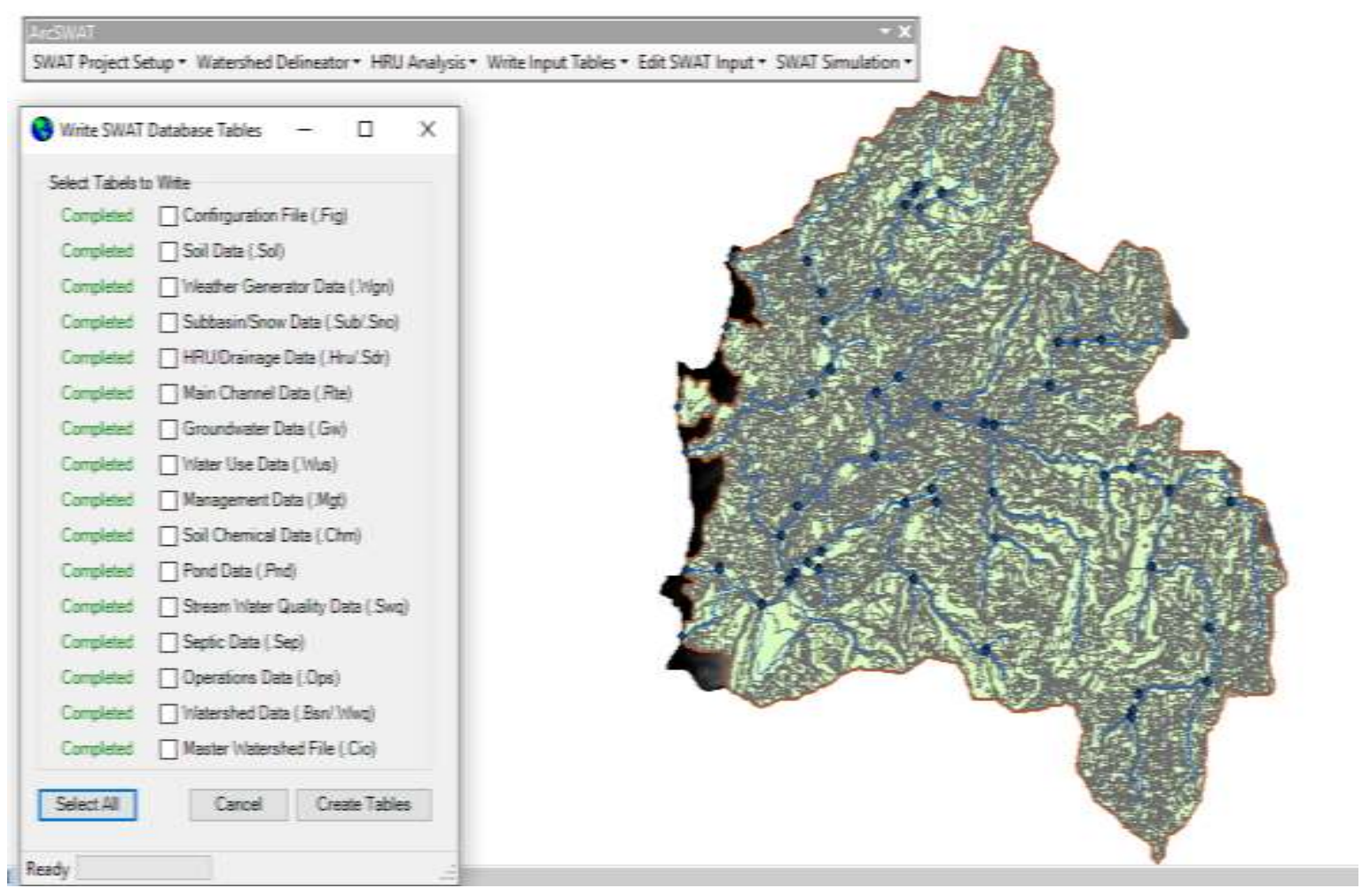

\section{Pembentukan Batas Sub Das Wilayah} DAS Karaje

Berdasarkan hasil yang diperolaeh jumlah luasan keseluruhan ialah 18.124,92 ha dan tebagi atas Sub DAS, sebanyak 101 dan memiliki masing-masing koordinat untuk dijadikan sebagai acuan peninjauan kondisi air dilapangan. Adapun sub das yang terkecil memiliki luas 4,77 ha, dan Sub DAS terbesar pada wilayah DAS Karajae memiliki luasan sebesar 844.38 ha. Didalam DAS ini juga memiliki enam (6) outlet jaringan sungai yang bermuara langsung ke laut.Terlihat pada tabel dan gambar 5.1 .7 pembagian Sub DAS pada Wilayah DAS Karajae.

\section{Identifikasi Lokasi Sumber-sumber Air di Wilayah DAS Karajae}

Telah dikemukan pada penjelasan sebelumnya, bahwa di Wilayah DAS Karajae memiliki 101 Sub DAS yang diperoleh dari hasil proses running SWAT yang dijadikan sebagai bahan analisis lebih lanjut. Adapun Sub DAS yang terpilih berdasarkan nilai ketersedian air yang tinggi dan debit air yang tersedia pada setiap bulannya peta dari sebaran unit lahan yang ada di DAS Karajae. 


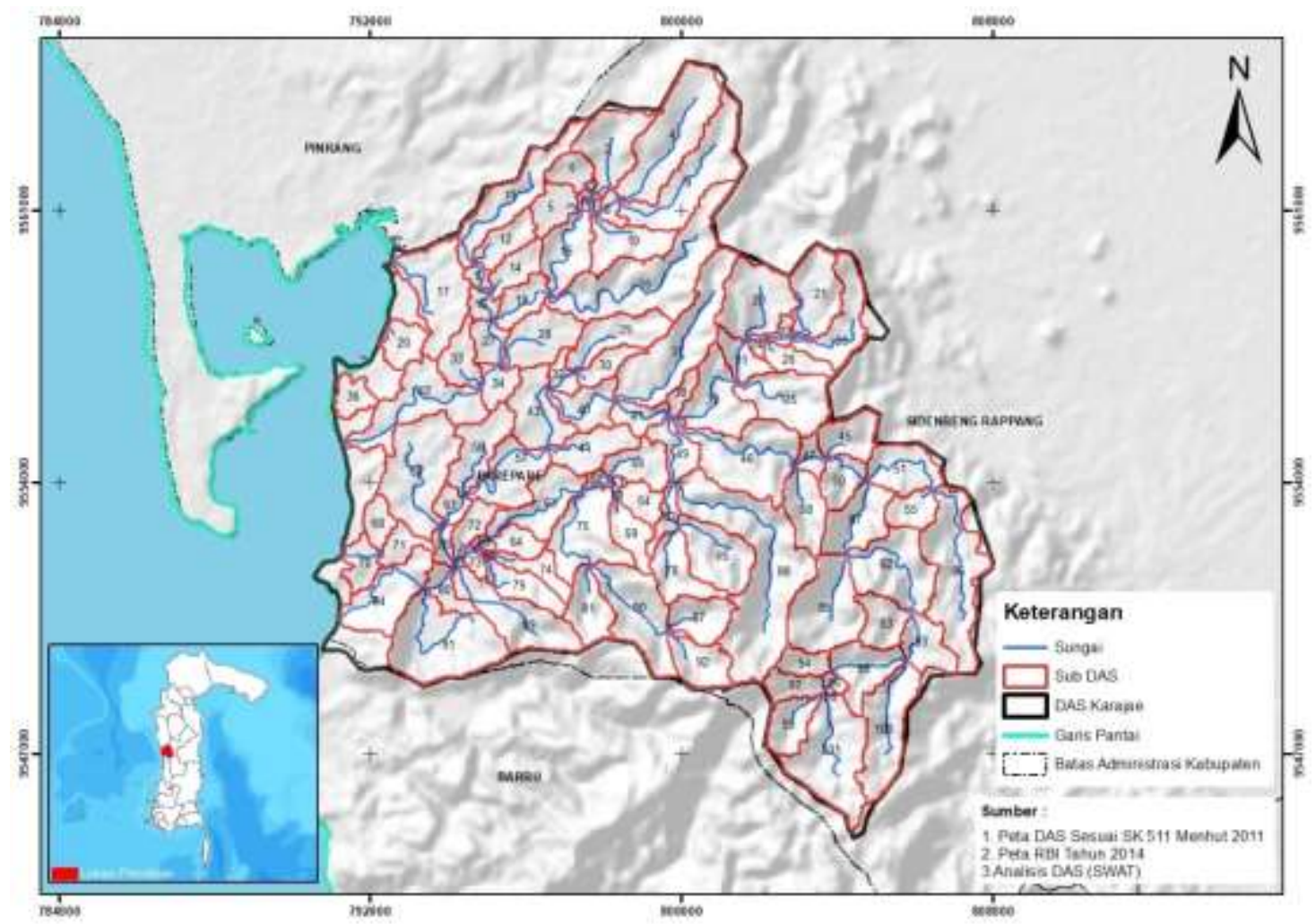

Nilai Air Bawah Tanah (Grown Water)

Air bawah tanah yang biasa di sebut Grown Water sangat berperang penting dalam ketersediaan air dikarenakan air bawah tanah adalah tempat berkumpulnya air yang akan digunakan pada saat kemarau, nilai yang didapatkan dari hasil analisis SWAT dengan rata-rata persentase $<15 \%$ dalam pertahunnya ini disebabkan banyaknya perubahan penggunaan lahan yang terjadi beberapa tahun terakhir yang menyebabkan rusaknya atau berkurangnya air bawah tanah yang seharusnya berperan penting dalam ketersediaan air. 


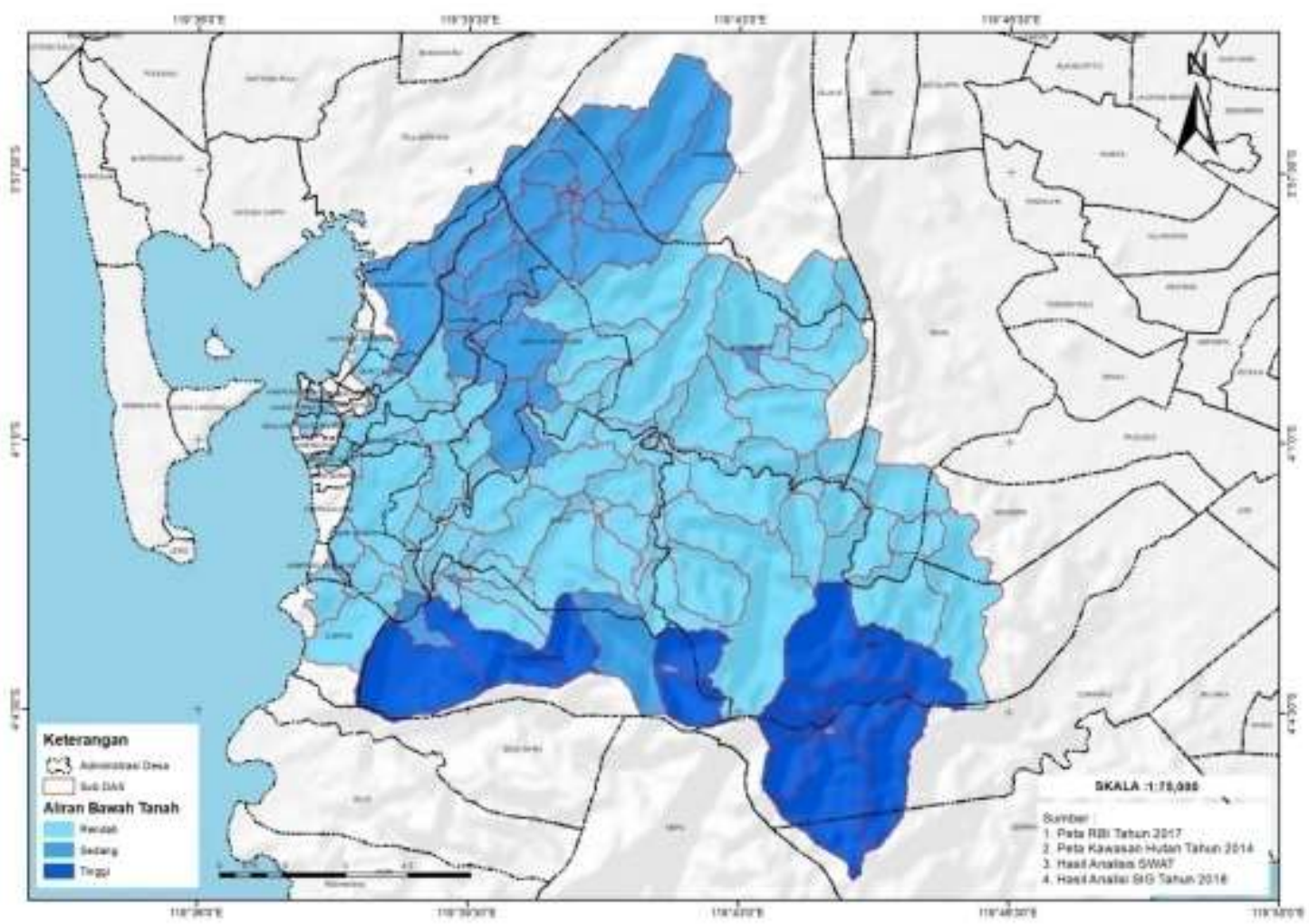

\section{KESIMPULAN DAN SARAN}

\section{Kesimpulan}

Adapun kesimpulan dari hasil penelitian ini :

1. Terdapat 11 jenis penutupan lahan yang ada di DAS Karajae yaitu :

- Hutan lahan kering dengan kerapatan rendah seluas $12,2 \%$

- Padang rumput seluas $6,5 \%$

- Perkebunan seluas 1,0\%

- Permukiman seluas $7,1 \%$

- Pertanian lahan kering seluas 35,1 $\%$

- Pertanian lahan kering campur semak seluas $12,5 \%$
- Sawah seluas $7,6 \%$

- Semak belukar seluas 17,0 \%

- Tambak seluas $0,2 \%$

- Tanah terbuka seluas $0,3 \%$

- Tubuh air seluas $0,5 \%$

2. Hasil identifikasi analisi SWAT diperoleh 4 Sub DAS pada 101 Unit Lahan sebagai sumber-sumber air yang memiliki ketersediaan air yang tinggi, ke 4 sub DAS yang dimaksud adalah Salo Lamare, Salo Caming, Salo Bacukiki dan Salo Labung.

3. Peta yang dibuat menggambarkan 101 Unit Lahan pada 4 Sub DAS yang ada di DAS Karajae, dan telah 
menunjukkan sumber-sumber air yang ada di DAS Karajae.

\section{Saran}

Saran yang disampaikan untuk penelitian ini adalah perlu dilakukan penelitian terkait perhitungan kebutuhan air baik kebutuhan air industri, domestik dan kebutuhan air lahan karena mengingat Kota Pare-Pare adalah sebagai Kawasan Pertumbuhan Ekonomi Terpadu (Kapet) yang menjadi pusat industri, perdagangan, pertanian, peternakan, energi dan transportasi laut

\section{DAFTAR PUSTAKA}

Adrionita. (2011). Analisis Debit Sungai dengan Model SWAT pada Berbagai Penggunaan Lahan di DAS Citarum Hulu Jawa Barat. Bogor: Institut Pertanian Bogor.

Arief, A. (2001). Hutan dan Kehutanan. Cetakan ke-5. Yogyakarta. Penerbit Kanisius.

Arsyad, S. (2010). Konservasi Tanah dan Air. Bogor: IPB Press.

Asdak, C. (2010). Hidrologi Dan Pengelolaan Daerah Aliran Sungai.
Yogyakarta. Gadjah Mada University Press.

Badan Standar Nasional. (2010). Klasifikasi Penutupan Lahan. Jakarta. BSNi.

Baja, S. (2012). Perencanaan Tata Guna Lahan dalam Pengembangan Wilayah Pendekatan Spasial \& Aplikasinya. Yogyakarta:: Penerbit Andi.

Bappenas, D. P. (2006). Prakarsa Strategis Pengelolaan Sumber Daya Air untuk Mengatasi Banjir dan Kekeringangan di Pulau Jawa. Jakarta. Bappenas.

Departemen Kehutanan. (2000). Handbook of Indonesian Forestry. Indonesia: Departemen Kehutanan.

Departemen Kehutanan. (2006). Glosarry Pengelolaan DAS. Makassar: Badan Litbang Kehutanan.

Ditjen Bina Pengelolaan DAS dan Perhutanan Sosial. (2014). Modul Tutorial SWAT:Soil \& Water Assesment Tool. Jakarta. Kementerian Kehutanan Republik Indonesia.

Ekadinata, dkk. (2008). Sistem Informasi Geografis untuk Pengelolaan Bentang Lahan Berbasis Sumber Daya Alam. Buku 1. Sistem Informasi Geografis dan Penginderaan Jauh menggunakan LWIS Open Source. Bogor: World Agroforestry Centre. 